
\title{
.
}

\section{ÁGUA: A PEGADA HÍDRICA NO SETOR ALIMENTAR E AS POTENCIAIS CONSEQUÊNCIAS FUTURAS}

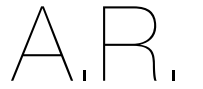
ARTIGO DE REVISÃO

1 Instituto Universitário de Ciências da Saúde da Cooperativa do Ensino Superior Politécnico

Universitário,

Rua Central de Gandra,

n. ${ }^{\circ} 1317$,

4585-116 Gandra,

Portugal

2 Associação Portuguesa de Nutrição,

Rua João das Regras,

n. ${ }^{\circ} 278$ e 284 , R-C

4000-291 Porto, Portugal

`Endereço para correspondência:

Catarina da Silva Gonçalo Instituto Universitário de Ciências da Saúde da Cooperativa do Ensino Superior Politécnico Universitário,

Universitário, Rua Central de Gandra, n. ${ }^{1} 13$ 4585-116 Gandra, Portugal catarinasgoncalo@gmail.com

Histórico do artigo

Recebido a 27 de junho de 2020 Aceite a 15 de setembro de 2020

\begin{abstract}
WATER: THE WATER FOOTPRINT IN THE FOOD SECTOR AND THE POTENTIAL FUTURE CONSEQUENCES
\end{abstract}

Ana Sofia Ferraz'; Catarina Gonçalo1"; Diana Serra'; Filipa Carvalhosa'; Helena Real',2

\section{RESUMO}

A água está presente em todos os processos e atividades humanas, entre os quais o setor de produção primária. O excesso da utilização da água nestes setores é uma problemática dos dias de hoje, que tem vindo a suscitar muitas questões acerca do futuro desta. Este artigo de revisão tem como propósito abordar a pegada hídrica em alguns setores alimentares para alertar os nutricionistas para a importância da pegada hídrica dos alimentos nas suas recomendações, bem como consciencializar a população sobre esta temática. O conceito de pegada hídrica deve ser transmitido à população, alertando sobre a importância do consumo de água consciente de forma a prevenir a sua escassez no futuro.

\section{PALAVRAS-CHAVE}

Água, Pegada hídrica, Produto alimentar, Reutilização

\section{ABSTRACT}

Water is present in all human activity, such as the primary sector. The overuse of water in those sectors is a major issue nowadays and it's been raising a lot of questions about its future.

This review article's purpose is to assess the water footprint in some sectors of the food industry so as to alert nutritionists of the water footprint of the ingredients they recommend, as well as raising public awareness of this issue.

The concept of water footprint should be passed on to the population, alerting of the importance of water that prevents its scarcity in the future.

KEYWORDS

Water, Water footprint, Food product, Reuse

\section{INTRODUÇÃO}

A superfície do planeta Terra é coberta por cerca de 70\% de água, sendo que $96 \%$ dessa água é retida em oceanos e apenas 2,5\% corresponde a água doce. Desta forma, a água disponível para o uso humano, incluindo atividades domésticas e agricultura, corresponde a menos de $1 \%$ da água da Terra (1). Ainda que seja um recurso renovável devido ao ciclo da água, a água no nosso planeta, da forma que o Homem necessita dela, é um bem limitado e cada vez mais escasso. Segundo a Organização das Nações Unidas (ONU), os recursos hídricos do nosso planeta enfrentam uma grande ameaça, estimando-se que até 2050, entre 3,5 a 4,4 mil milhões de pessoas terão acesso limitado à água, incluindo a população que reside nas grandes cidades (2). O elevado consumo de água pela população e o aumento urbano e populacional criaram ao longo dos tempos diversos impactos, incluindo a necessidade de novas tecnologias no tratamento e gestão das águas. No entanto, apesar destas necessidades terem sido atendidas, a consciencialização por parte da população em relação aos gastos da água e à sua escassez, não evoluiu tão rápido como as respostas às suas necessidades (3). Desta forma, o impacto do desregramento da utilização da água ao longo dos anos tem sido cada vez mais notório, como a degradação da qualidade da água, aumento das doenças veiculadas pela água, diminuição da água disponível per capita, o aumento do custo da produção dos alimentos e do custo do tratamento das águas (4). Porém, uma vez que a água é um bem essencial e o seu acesso é um direito básico a todos os seres humanos, os custos inerentes ao seu abastecimento e saneamento têm de apresentar valores acessíveis a toda a população, o que por si se torna um fator para a sua desvalorização e recorrente desperdício $(4,5)$.

A partir desta perspetiva, atualmente surgem cada vez mais problemáticas associadas à chamada "água virtual", sendo esta referente à água que é utilizada como matéria-prima essencial para a produção de quase tudo o que consumimos e usamos, tais como, alimentos, roupa, pecuária, automóveis e até eletrodomésticos, entre outros (6). 
Um dos principais setores que mais utiliza água para a sua produção é o setor alimentar que abarca grande quantidade de água e de poluição contribuindo para a pegada hídrica e ecológica de forma cada vez mais notória $(4,7)$. Assim, com o aumento da população, as necessidades de alimentos aumentam, tornando-se cada vez mais emergente tomar medidas sustentáveis para regrar a utilização da água neste setor (4). Para além das preocupações em produzir em quantidade suficiente e com a qualidade e segurança devidas, atualmente a questão da sustentabilidade ambiental ganha cada vez mais peso no setor alimentar $(4,7)$.

Sendo esta problemática cada vez mais emergente no nosso dia-a-dia, este artigo aborda os conceitos associados à pegada hídrica, bem como alerta para o consumo de água associado a alguns alimentos. Apresenta também alguns exemplos de reutilização de água com o intuito de demonstrar o impacto a que estas alterações podem levar. Por fim, aborda-se uma perspetiva do futuro se nada for alterado. Em suma, é fundamental a consciencialização da influência da produção alimentar na pegada hídrica, de forma a que a população tome decisões mais adequadas neste âmbito.

A pesquisa bibliográfica foi realizada em bases de dados e bancos de depósito de artigos e teses, nacionais e internacionais: Pubmed, Scielo e Rcaap com as seguintes palavras-chave: pegada hídrica/ water footprint, produtos alimentares/food products, reutilização/reuse, consumo de água/water consumption e nutricionista/nutritionist, entre abril e junho de 2020. Procedeu-se à consulta de páginas eletrónicas de instituições de referência para a temática, como a Associação Portuguesa de Nutrição, Food and Agriculture Organization, Water footprint, Instituto nacional de estatística e Pordata.

\section{Pegada Hídrica}

Em 2002, surge o conceito de pegada hídrica como indicador relativo de consumo de água, tendo como objetivo contabilizar a quantidade de água utilizada nos bens e serviços que são consumidos pelos indivíduos, isto é, a pegada hídrica permite quantificar o consumo de água total ao longo de toda a cadeia de produção $(3,8)$. A pegada hídrica de um indivíduo pode ser calculada para um indivíduo ou para uma comunidade (3). A pegada hídrica total é constituída por três componentes: pegada hídrica azul, pegada hídrica verde e pegada hídrica cinza. A pegada hídrica azul é definida como indicador de consumo de água doce superficial e/ou subterrânea, estando diretamente relacionada com as variáveis hidrológicas que regulam o ciclo hidrológico. Esta pegada inclui a água evaporada, a água incorporada no produto, a água que não retorna para a área de captação e a água que não retorna no mesmo período. O maior consumo global referente a esta pegada é no setor agrícola. A pegada hídrica verde é um indicador do uso da água proveniente da precipitação e é armazenada temporariamente no solo ou permanece temporariamente na superfície do solo. Por outras palavras, esta pegada representa o total de água oriunda da chuva que é consumida durante a produção. A pegada hídrica cinza indica o grau de poluição da água doce que está relacionada com o processo de produção (9). A pegada hídrica também pode ser classificada em pegada hídrica direta ou indireta, bem como pegada hídrica externa ou interna. A pegada hídrica direta está relacionada com o consumo de água e poluição referente ao uso da água na casa ou no jardim. Por outro lado, a pegada hídrica indireta está relacionada ao consumo de água e poluição referente à produção de bens e serviços utilizados pelo consumidor. Relativamente a empresas, a maior parte da pegada hídrica advém da pegada hídrica indireta, isto é, da cadeia de abastecimento $(3,9)$. A pegada hídrica externa é definida pela quantidade de recursos hídricos utilizados fora do país para a produção de bens e serviços que são consumidos pelos habitantes. Já a pegada hídrica interna diz respeito à utilização de recursos hídricos do país para a produção de bens e serviços que são consumidos pelos habitantes $(8,9)$.

Os países mais desenvolvidos têm um maior consumo de produtos e, consequentemente, uma maior pegada hídrica. Desta forma, a nível mundial, os Estados Unidos são os que apresentam uma maior pegada hídrica (8). A nível europeu, a Tabela 1 apresenta estimativas relativas aos 10 países com maior pegada hídrica per capita (10).

Relativamente à sustentabilidade da pegada hídrica, esta está dependente de fatores locais, como por exemplo, as características hídricas da região. Assim sendo, a pegada hídrica pode ser um indicador de sustentabilidade, através do controlo do impacto humano sobre o ambiente (3).

\section{Consumo de Água}

Uma vez que, a pegada hídrica verde diz respeito à maior percentagem a nível europeu (11), os principais alimentos responsáveis por tal facto são apresentados nos Gráficos 1 e 2 (12). Assim, em seguida será abordada esta pegada em diferentes setores alimentares.

\section{Agricultura}

Tendo em conta todas as atividades económicas praticadas pelo ser humano, a agricultura é a que utiliza mais água doce, isto é, a água proveniente das chuvas e de outras precipitações que caem diretamente na terra (13). Um dos contributos significativos na utilização dos recursos hídricos é o da irrigação das culturas. Em países do sul da Europa, onde Portugal está inserido, as condições áridas ou semiáridas obrigam ao aumento deste recurso na irrigação, traduzindo-se em cerca de $80 \%$ da água consumida (14).

\section{Tabela 1}

Países europeus com maior pegada hídrica per capita, tendo em conta a pegada hídrica total e a sua população, em 2011(10)

\begin{tabular}{|c|c|c|c|}
\hline PAis & POPULAÇÃO & PEGADA HÍDRICA TOTAL & PEGADA HÍDRICA PER CAPITA \\
\hline Portugal & 10.3 milhões & 26000 & 6900 \\
\hline Espanha & 40.8 milhões & 100000 & 6700 \\
\hline Hungria & 10.2 milhões & 24000 & 6500 \\
\hline Sérvia & 10.7 milhões & 26000 & 6500 \\
\hline Grécia & 10.9 milhões & 26000 & 6400 \\
\hline Bulgária & 7.99 milhões & 18000 & 6300 \\
\hline Itália & 57.5 milhões & 130000 & 6300 \\
\hline Islândia & 282000 & 590 & 5800 \\
\hline Bélgica & 10.4 milhões & 20000 & 5200 \\
\hline
\end{tabular}




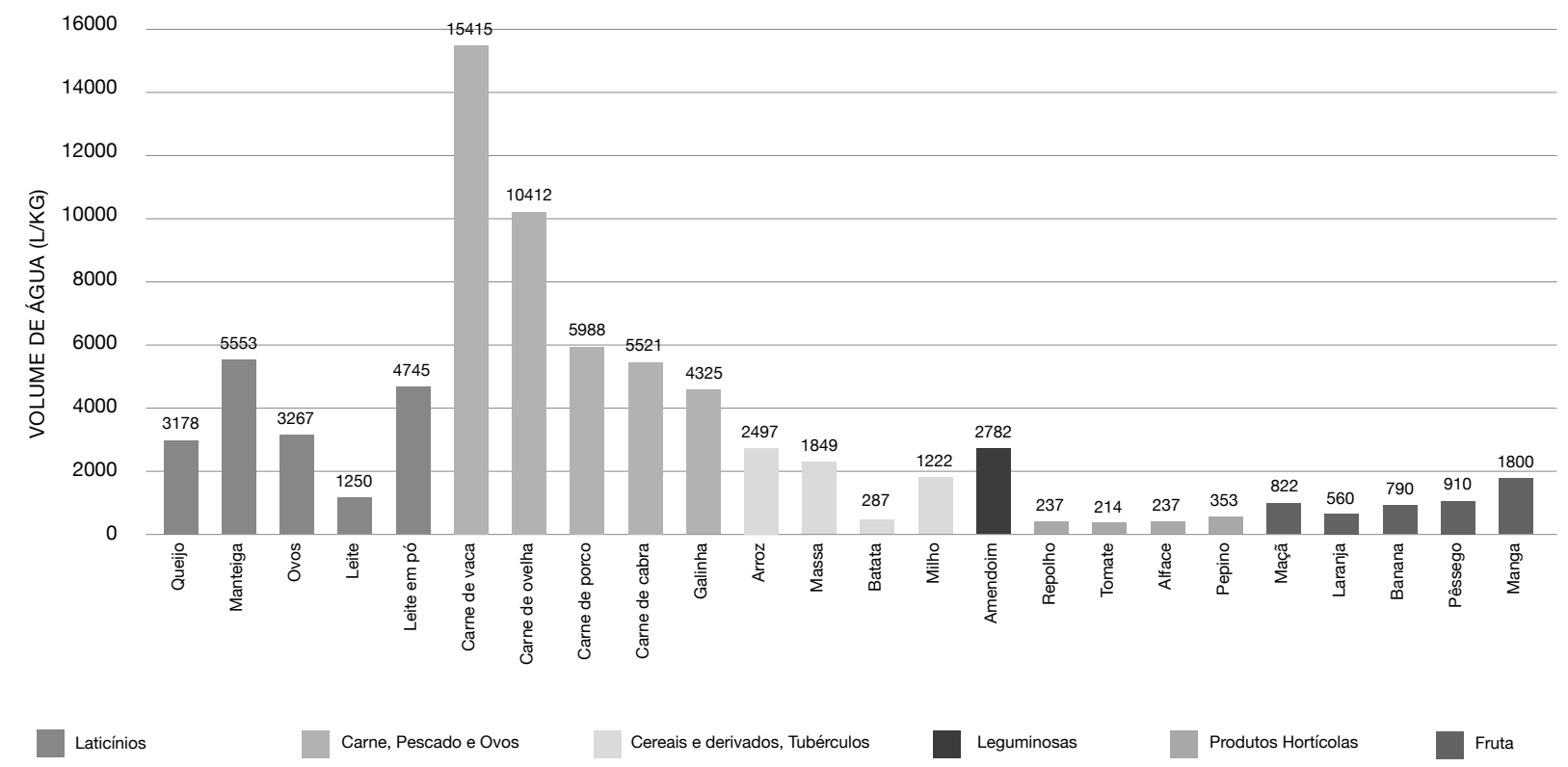

\section{Gráfico 2}

Pegada hídrica média de alguns produtos processados (12)

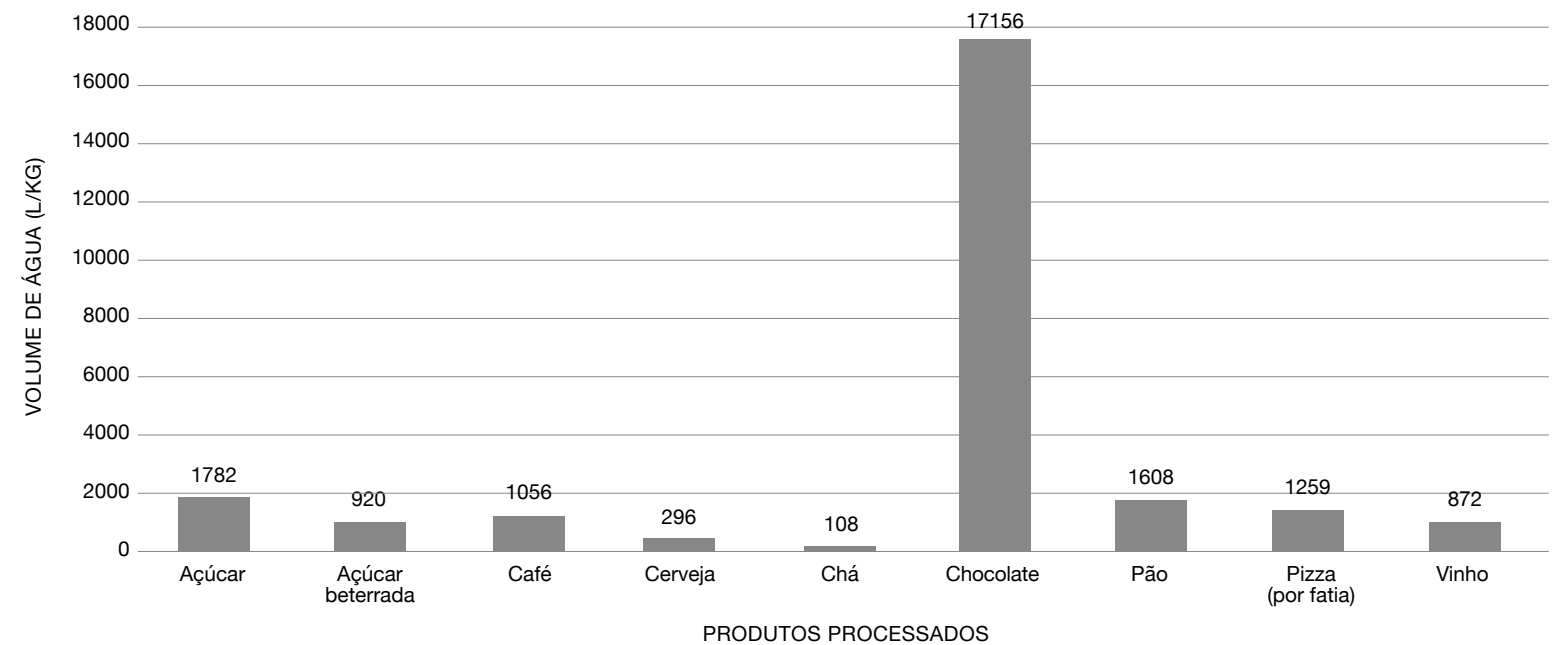

Carne

Os alimentos de origem animal são, entre os vários sistemas de produção de alimentos, os que apresentam uma menor probabilidade de sustentabilidade, sobretudo devido ao seu consumo de energia e de água ao longo de toda a cadeia de produção. O processo de produção da ração para a alimentação dos animais é o principal destino do total de água utilizada (15-17).

No que se refere à carne branca, mais concretamente ao frango, enquadrando-se num sistema industrial de produção, este leva 10 semanas até ser abatido e em média, cada frango pesa 1,7 kg e consome 3,3 kg de ração, necessitando de 30 litros de água para suprir as suas necessidades hídricas. No final, o consumo de água total é estimado em 3900 litros tendo em conta toda a água que é necessária ao longo da cadeia de produção. Sumariamente, para $1 \mathrm{~kg}$ de frango são necessários cerca de 20 litros de água (17).

Relativamente à carne vermelha, em especial a carne bovina, enquadrando-se novamente num sistema industrial de produção, são necessários em média cerca de 3 anos até ao abate do animal. Estima-se que uma vaca que consuma $1300 \mathrm{~kg}$ de ração e $7200 \mathrm{~kg}$ de forragem, irá precisar de 24000 litros de água para se hidratar e de 7000 litros para a limpeza geral. Assim, para a produção de $1 \mathrm{~kg}$ de carne bovina são necessários 15500 litros de água (18). Em suma, a pegada hídrica de um animal é calculada baseando-se no consumo de água durante toda a sua vida, incluindo a que é utilizada na higiene, na alimentação e no consumo propriamente dito (3).

\section{Pescado}

A pesca é uma das principais fontes de proteína animal, mas devido ao estado de sobre-exploração da maior parte dos recursos pesqueiros tradicionais, a importância das aquiculturas começou a ter um papel socioeconómico preponderante (18). O grande desafio na aquicultura é desenvolver uma aquicultura sustentável, já que a atividade exige 
recursos naturais tais como, energia, solo e água (19). A indústria responsável pelo processamento do pescado recorre a um grande volume de água potável que é utilizada em quase todas as etapas do processamento, entre elas, a insensibilização, o abate, a depuração, a limpeza de superfícies, a evisceração e a filetagem. A utilização de água pode estar ainda relacionada com as diferentes características físicas da espécie processada, escala de produção, tecnologias adotadas no processamento e o grau de comprometimento da indústria com as práticas para uma produção sustentável (20).

A preocupação não é somente com a água que entra no processo, mas também com aquela que sai, porque o volume de água utilizada pela indústria está diretamente ligado à quantidade de efluente produzido. $O$ efluente gerado na indústria de processamento de pescado apresenta uma elevada carga orgânica e, por isso, o tratamento adequado é fundamental (21). A pegada hídrica, amplamente estudada na produção de produtos cárneos e agrícolas, é ainda desconhecida no setor da aquicultura (22).

\section{Leguminosas}

Atualmente, no que respeita aos produtos alimentares, a sustentabilidade faz parte dos critérios de seleção dos consumidores (23). As leguminosas produzidas em Portugal são uma excelente resposta a esta problemática, pois possuem custos ambientais de produção inferiores a outros alimentos. Comparativamente à carne, as leguminosas possuem uma pegada hídrica inferior a $88 \%$. Em suma, para a produção de $1 \mathrm{Kg}$ de leguminosas são gastos cerca de $4.055 \mathrm{~L}$ de água $(23,24)$.

\section{Laticínios}

A indústria láctea caracteriza-se por consumir grandes quantidades de água ao longo da sua cadeia de produção, pois a sua utilização está normalmente vinculada à garantia das condições sanitárias e de higiene necessárias. A água é sobretudo utilizada nos processos que envolvem os condensadores e as caldeiras, nas perdas físicas, no sistema clean in place (CIP), no arrefecimento e na limpeza (25).

De um modo geral, a quantidade e a qualidade da água consumida numa indústria de laticínios depende do produto e da capacidade de produção. Destaca-se também a idade das instalações, atendendo a que as indústrias com instalações tecnológicas mais antigas ou desatualizadas, consomem mais recursos naturais do que as mais recentes, uma vez que, os equipamentos desatualizados possuem uma maior probabilidade de provocar perdas e ruturas com mais frequência. A pegada hídrica do leite estima que sejam necessários 1020 litros de água para se produzir 1 litro de leite e, em média, 1 litro de leite de vaca produz $95 \mathrm{~g}$ de queijo. Assim, a produção de $1 \mathrm{~kg}$ de queijo exige exige o gasto de 5060 litros de água e para 1 kg de manteiga são necessários 18000 litros de água, sendo que a produção de ambos está diretamente relacionada com a quantidade de leite utilizado (12).

\section{Reutilização da Água}

Os períodos de seca aliados à escassez de água são a motivação de alguns países para a reutilização de água. Esta é uma ferramenta cada vez mais ponderada com a finalidade de reduzir substancialmente quer as necessidades de abastecimento de água, quer o seu custo associado (7). Assim sendo, a reutilização da água torna-se importante na indústria alimentar, dado que a água tem diversas finalidades nesta indústria, como por exemplo, pode estar em contacto direto/indireto com o alimento, pode fazer parte do processamento de um outro alimento (imersão, branqueamento, aquecimento e pasteurização), ou até mesmo ser o próprio ingrediente $(7,26)$. De realçar, que a indústria alimentar quando comparada a outros setores industriais gasta muito mais água por tonelada de produto (27).

De acordo com a Diretiva 98/83/CE, a água utilizada no processamento de alimentos deve conter um padrão tão elevado como o da água potável. Assim, surgem vários obstáculos para a reutilização de água, sendo os mais cruciais os riscos microbiológicos, que devem ser garantidos e monitorizados constantemente pelo ponto crítico de controlo de análises de perigos (HACCP) (27). Deve-se mencionar que o termo "reutilização" da água corresponde à recuperação da água numa determinada etapa de processamento e a sua posterior utilização num processamento de alimentos (7).

O método utilizado para o tratamento da água depende de diversos critérios, nomeadamente, custos, segurança, qualidade da água e capacidade de tratamento da água (7). Torna-se, portanto, necessária uma compreensão de vários fatores que influenciam a reutilização da água, de modo a que os regulamentos existentes possam ser revigorados ou até adoção de novos regulamentos (12).

A reutilização da água depende do método utilizado para recuperar a água, da sua natureza e do seu uso final. São várias as estratégias que podem ser adotadas para reutilizar ou reduzir o consumo da água. Por um lado, a água utilizada na lavagem das frutas e produtos hortícolas, ou a água utilizada na manteiga e no queijo, podem ser recicladas, isto é, ser usadas na mesma operação do processamento. Da mesma forma, a água utilizada na pasteurização pode também ser reutilizada, dependendo do binómio temperatura/tempo, que ditarão o uso final dessa mesma água (26). Por outro lado, também é possível reduzir o consumo de água no processamento dos alimentos, através de operações unitárias que utilizem menos água, como por exemplo, hastes pulverizadas para lavar tomates e uso de vapor de água para limpar frascos de vidro de conservas de frutas e produtos hortícolas, assim como otimização da água utilizada durante o processamento e limpeza. De notar, que a irrigação agrícola é a principal aplicação das águas reutilizadas (7), sendo que o líder mundial em reutilizar água, Israel, trata aproximadamente $86 \%$ das águas residuais para esse mesmo fim (12).

Segundo alguns estudos, existe potencial na reciclagem e reutilização da água na indústria dos alimentos, visto que demonstraram que seria possível reduzir o uso da água cerca de 20 a 50\% (7).

As vantagens ambientais associadas à reutilização da água são variadas, particularmente, na redução da pressão de aquíferos em stress, na redução dos gastos e uso de fertilizantes devido aos nutrientes restantes nessa água e, até mesmo, maiores rendimentos de algumas culturas. Porém, sabe-se também que a reutilização extensiva e prolongada dessa água tem riscos ambientais e fitossanitários que podem potenciar riscos para a saúde pública, pois os contaminantes microbiológicos, bactérias resistentes a antibióticos, metais pesados, bem como produtos farmacêuticos podem permanecer na água reutilizada. Desta forma, torna-se impreterível que existam regulamentos e políticas relativamente à reutilização da água, de modo a que esta possa surgir como uma solução viável e sustentável para diversas populações (26).

\section{O Que Poderá Acontecer se Nada Mudar?}

Desde 1960 até aos dias de hoje, o consumo de água multiplicou havendo nesse ano 3 mil milhões de habitantes. Atualmente existem 7.6 mil milhões e calcula-se que em 2100, seremos 11 mil milhões de pessoas (28). Tendo em consideração estes números, a escassez da água já tem vindo a criar tensões entre países, tal como aconteceu com o petróleo no passado (29). A desertificação, devido às mudanças climáticas, também poderá originar conflitos internacionais, pois para 
cada grau de aumento na temperatura global, aproximadamente $7 \%$ da população mundial terá uma diminuição de cerca de $20 \%$ no acesso aos recursos hídricos renováveis (30).

Em Portugal, já existem algumas noções de que a água não é um bem inesgotável e que esta é cada vez mais escassa (31). No entanto, a maioria das pessoas mantêm os mesmos hábitos sabendo qual o preço a pagar futuramente se nada mudar. Atualmente a humanidade utiliza 50\% da água doce do planeta e a tendência é que em 40 anos esse valor passe a $80 \%(30)$.

O mínimo de água necessária por dia, per capita é de 20L, porém os valores reais são diferentes, sendo que no mundo cerca de $1.1 \mathrm{mil}$ milhões de pessoas não tem acesso a água potável e 2.6 mil milhões não têm acesso a saneamento básico de água. Por exemplo, por dia, em Moçambique é utilizado per capita menos de $10 \mathrm{~L}$ de água, na Europa 200-300 L e nos Estados Unidos 575 L (28).

Diariamente, rios, riachos, lençóis de água e aquiferos são contaminados pelos esgotos mal tratados, pela utilização de agrotóxicos e pela eliminação de lixo tóxico das indústrias (30). Assim, segundo a ONU, se não forem tomadas medidas até 2030, as reservas hídricas podem reduzir até $40 \%$, uma vez que aproximadamente $20 \%$ dos aquíferos são explorados de forma excessiva, o que poderá originar erosões do solo e a entrada de água salgada nesses reservatórios, bem como o acesso à água potável a nível mundial será ainda mais reduzido, estimando-se que cerca de 5 mil milhões biliões de pessoas sofrerão com a falta de água e saneamento básico em 2030 (30).

Na agricultura, se não houver um aprimoramento das técnicas utilizadas, até 2050 o consumo de água poderá aumentar até 90\% (30).

\section{ANÁLISE CRÍTICA}

Neste artigo é evidenciado que algumas partes do setor alimentar são responsáveis por uma grande quantidade de água consumida, sobretudo na produção animal, nomeadamente, na produção de carnes. Os produtos de origem vegetal comparativamente com os produtos de origem animal têm uma pegada hídrica menor (31), tal como se pode verificar a partir do Gráfico 1. Assim, o consumo destes produtos de origem vegetal deve ser motivado pelos nutricionistas, apelando nas suas recomendações um consumo mais frequente de produtos hortofrutícolas e um consumo menos frequente de carnes (carnes brancas semanalmente e de carnes vermelhas mensalmente), de forma a contribuir para uma redução da pegada hídrica e, consequentemente, uma redução dos danos ambientais que esta causa (32).

Apesar de não ser objetivo deste artigo, no Gráfico 2 são apresentadas estimativas de valores de pegadas hídricas de alguns produtos processados, de forma a mostrar que alguns podem ser bastante mais impactantes que alguns provenientes da produção primária, estando o maior gasto de água associado ao próprio processamento industrial, o que corrobora a importância de se limitar o consumo de alimentos mais processados, sobretudo os grandes fornecedores de açúcar, sal e gordura.

Numa perspetiva europeia, Portugal é o país que apresenta uma maior pegada hídrica per capita, no entanto, a pegada hídrica total não é a mais alta da Europa. A pegada hídrica total poderá não ser tão elevada pelo facto de em Portugal existirem menos setores das indústrias, da agricultura, do comércio e outros serviços que, como já referido, aumentam a pegada hídrica, devido ao elevado consumo de água necessária nas suas atividades (33). Em suma, a nível mundial, muitos são os países que apresentam graves problemas de disponibilidade de água, devido ao facto da população mundial estar a aumentar, bem como da inexistência da distribuição equitativa da água (8).

\section{CONCLUSÕES}

Para evitar as consequências provocadas pelas pegadas hídricas e pelo excesso de consumo de água por parte da população, torna-se crucial que seja adotada uma nova forma de percecionar a água. Assim, é necessário reconhecer as diversas dimensões da problemática tendo em conta valores éticos, sociais, políticos, económicos e ambientais envolvidos. Será fundamental envolver todas as partes interessadas e procurar adequar a produção no setor primário a um uso mais eficiente dos recursos hídricos, procurando ajustar, por exemplo, o tipo de alimento produzido aos recursos hídricos que a região de produção consegue fornecer, para se obter um equilíbrio maior.

Por outro lado, será imperioso promover uma maior literacia da população e dos nutricionistas sobre a pegada hídrica, de forma a que se promovam melhores escolhas e recomendações alimentares mais conscientes, no sentido de se realçar a importância de se ter uma alimentação mais poupadora de água, ao nível da produção alimentar que the deu origem.

\section{REFERÊNCIAS BIBLIOGRÁFICAS}

1. Sapkota, AR. Water Reuse, Food Production and Public Health: Adopting Transdisciplinary, Systems-Based Approaches to Achieve Water and Food Security in a Changing Climate. Environmental Research 171. 2019: 576-80.

2. Dia Mundial da Água. Nações Unidas - ONU Portugal [lnternet]. c2020 [citado 2020 Mar 5]. Disponível em: https://unric.org/pt/dia-mundial-da-agua.

3. Silva VPR, Aleixo DO, Dantas NJ, Maracajá KFB, Araújo LE. Uma medida de sustentabilidade ambiental: pegada hídrica. Revista brasileira engenharia agrícola ambiental. 2013;17(1):100-5.

4. Giacomin GS, Ohnuma Jr AA. A pegada hídrica como instrumento de conscientização ambiental. Remoa. 2012;7(7):1517-26.

5. Branco A. Novos paradigmas para a gestão da água e dos serviços de água e saneamento: o caso de Portugal [dissertação]. Universidade de lisboa faculdade de ciências; 2007.

6. Bleninger T, Kotsuka LK. Conceitos de água virtual e pegada hídrica: estudo de caso da soja e óleo de soja no Brasil. Recursos Hídricos. 2015 Mai;36(1):15-24.

7. Casani S, Rouhany M, Knøchel S. A Discussion Paper on Challenges and Limitations to Water Reuse and Hygiene in the Food Industry. Water Research. 2005 Mar;39(6):1134-46.

8. Seixas V. Análise da pegada hídrica de um conjunto de produtos agrícolas [dissertação]. Faculdade de Ciências e Tecnologia. 2011.

9. Hoekstra AY, Chapagain AK, Aldaya MM,, Mekonnen MM. The Water Footprint Assessment Manual : Setting the Global Standard. Routledge; 2012.

10. waterfootprint.org [Internet]. Enschede: National Water Footprint Explorer. [citado 2020 Abr 14]. https://www.waterfootprintassessmenttool.org/national-explorer/.

11. Hoekstra AY, Mekonnen MM. The water footprint of humanity, Proceedings of the National Academy of Sciences. 2012; 109(9): 3232-37. http://waterfootprint.org/en/ resources/water-footprint-statistics/.

12. Waterfootprint.org [Internet]. Enschede: Pegada hídrica do produto. c2017 [citado 2020 Abr 15]. Disponível em: https://waterfootprint.org/en/resources/interactive-tools/ product-gallery/.

13. Godfray HCJ, Aveyard P, Garnett T, Hall JW, Key TJ, Lorimer J, et al. Meat consumption, health, and the environment. Science. 2018 Jul;361(6399):5324.

14. A água na agricultura [Internet]. Copenhagen: Agência Europeia do Ambiente. [citado 2020 Abr 4]; Disponível em: https://www.eea.europa.eu/pt/articles/a-aguana-agricultura.

15. Borsato E, Tarolli P, Marinello F. Sustainable patterns of main agricultural products combining different footprint parameters. J Clean Prod. 2018 Abr;179:357-67.

16. Nascimento EP, Vianna JNS, Motta LG, Drummond JA, Queiroz AC, Mello NA, et at. Economia, meio ambiente e comunicação. 2006.

17. Costa JM, Monteiro MF (Divisão de Alimentação Animal da Direção de Serviços de Nutrição e Alimentação da DGAV). Produção nacional de alimentos compostos 
para animais - 2018. Lisboa (PT). 2019.

18. Maracajá KFB, Silva VPR, Neto JD. Pegada hídrica dos consumidores vegetarianos e não vegetarianos. Qual Rev Eletrônica. 2013 Jan;14(1):1-18.

19. FAO. The State of World Fisheries and Aquaculture 2018 - Meeting the sustainable development goals. Rome (IT); 2018.

20. Fernando K. Panorama da aquicultura - Sustentabilidade. 2010 Jun;20(119):16-23. 21. Arvanitoyannis IS, Kassaveti A. Fish industry waste: treatments, environmental impacts, current and potential uses. Int J Food Sci Technol. 2008;43(4):726-45.

22. Wojcikiewicz CA, Nascimento FV, Garbossa LHP, Lapa KR, Arana LAV. Pegada hídrica cinza de sistema de cultivo intensivo de camarão-branco em água salobra. Bol Inst Pesca. 2017;43(3):426-36.

23. Hoekstra AY. The hidden water resource use behind meat and dairy. Animal Frontiers 2. $2012 ; 2: 3-8$.

24. FAO. Action plan for the international year of pulses- nutritious seeds for a sustanaible future. 2016

25. Instituto de Pesca [Internet]. São Paulo: No Dia Mundial da Água, Instituto de Pesca apresenta projeto inédito que busca determinar pegada hídrica na aquicultura. [citado 2020 Abr 8]. Disponível em: https://www.pesca.agricultura.sp.gov.br/ip-na-midia/324instituto-de-pesca-apresenata-projeto-inedito-que-busca-determinr-pegada-hidricana-aquicultura.

26. Silva DJP (Universidade federal de viçosa, departamento de tecnologia de alimentos, ciência e tecnologia de alimentos). Programa de conservação e recurso de água - PCRA. Viçosa (PT). 2011.

27. Casani S, Knøchel S. Application of HACCP to Water Reuse in the Food Industry. Food Control. Junho de 2002; 13(4-5):315-27.

28. Mavrov V, Bélières E. Reduction of Water Consumption and Wastewater Quantities in the Food Industry by Water Recycling Using Membrane Processes. Desalination. 2000;131(1-3):75-86.

29. Portal Saneamento Básico [Internet]. Desperdício de água no planeta - Causas e Consequências; c2017 [citado 2020 Abr 20]. Disponível em: https://www. saneamentobasico.com.br/desperdicio-de-agua-no-planeta/.

30. Borba ALS, Costa MR, Lima FB (Pesquisadores em Geociências da CPRM Companhia de Pesquisas de Recursos Minerais). A proteção das águas: recurso natural limitado. 2018.

31. Águas de Portugal. Atitudes e Comportamentos dos Portugueses face à Água Relatório Quali-Quantitativo. 2018.

32. Harmon AH, Gerald BL. Position of the American Dietetic Association: food and nutrition professionals can implement practices to conserve natural resources and support ecological sustainability. Journal of American Dietetic Association. 2007;107(6):1033-43.

33. PORDATA [Internet]. Lisboa: Valor acrescentado bruto: total e por setor de atividade económico. 2019 [citado 2020 Abr 21]. Disponível em: https://www.pordata.pt/ Europa/. 